\title{
A Pax3/Pax7-dependent population of skeletal muscle progenitor cells
}

\author{
Frédéric Relaix ${ }^{1}$, Didier Rocancourt ${ }^{1}$, Ahmed Mansouri ${ }^{2}$ \& Margaret Buckingham ${ }^{1}$
}

During vertebrate development, successive phases of embryonic and fetal myogenesis lead to the formation and growth of skeletal muscles ${ }^{1}$. Although the origin and molecular regulation of the earliest embryonic muscle cells is well understood ${ }^{2}$, less is known about later stages of myogenesis. We have identified a new cell population that expresses the transcription factors $\operatorname{Pax} 3$ and Pax7 (paired box proteins 3 and 7) but no skeletal-musclespecific markers. These cells are maintained as a proliferating population in embryonic and fetal muscles of the trunk and limbs throughout development. Using a stable green fluorescent protein (GFP) reporter targeted to $\mathrm{Pax} 3$, we demonstrate that they constitute resident muscle progenitor cells that subsequently become myogenic and form skeletal muscle. Late in fetal development, these cells adopt a satellite cell position characteristic of progenitor cells in postnatal muscle. In the absence of both Pax3 and Pax7, further muscle development is arrested and only the early embryonic muscle of the myotome forms. Cells failing to express Pax3 or Pax7 die or assume a nonmyogenic fate. We conclude that this resident Pax3/Pax7dependent progenitor cell population constitutes a source of myogenic cells of prime importance for skeletal muscle formation, a finding also of potential value in the context of cell therapy for muscle disease.

During the onset of skeletal myogenesis in the embryo, Pax3 is required for the survival of the ventro-lateral dermomyotome, the part of the somite that gives rise to hypaxial body $y^{3,4}$ and limb musculature. Pax3 is also implicated in the determination of myogenic cell fate, acting through $\mathrm{MyoD}^{6}$. In the absence of the myogenic regulatory factors MyoD, Myf5 and Mrf4 (ref. 7), skeletal muscle does not form and no myogenic cells are present ${ }^{8}$. Most of the functions of $\operatorname{Pax} 3$ can be replaced by its paralogue $\operatorname{Pax} 7$ (ref. 9). However, Pax7, which is also expressed in the somite, is only essential for myogenesis after birth, when it is expressed in satellite cells (the progenitors of adult skeletal muscle) $)^{10,11}$.

Pax3 is first expressed in the presomitic mesoderm and this expression is maintained in the somitic epithelium of the dermomyotome $^{12-15}$ (Fig. 1a). However, at embryonic day (E) 10.5, Pax3 is also detected (by immunohistochemistry) in the myotome, the first skeletal muscle to form ${ }^{16}$ (Fig. 1b, c). In less mature posterior somites, this expression is first observed in a few cells lying under the epithelial dermomyotome (Fig. 1a), whereas in more mature anterior somites, Pax3-expressing cells are found throughout the myotome (Fig. 1b, c). The number of Pax3-positive $\left(\mathrm{Pax}^{+}\right)$myotomal cells increases as the central dermomyotome loses its epithelial structure (Fig. 1d (middle and right panels) and e), suggesting that they arise directly from the central dermomyotome. Similar results were observed for Pax7, which is first expressed in the central dermomyotome ${ }^{9,17}$ (Supplementary Fig. S1a) and then co-localizes with Pax3-positive cells in the myotome (Fig. 1e, right panel), where about $87 \%$ of cells are
$\mathrm{Pax}^{+}{ }^{+} \mathrm{Pax} 7^{+}, 10 \%$ are $\mathrm{Pax} 3^{+}$only, and $3 \%$ are $\mathrm{Pax} 7^{+}$only. Recent experiments in the chick embryo show that $\mathrm{Pax} 3^{+} \mathrm{Pax} 7^{+}$cells in the myotome derive from the dermomyotome ${ }^{25}$

At E10.5, expression of the myogenic determination factor Myf5, visualized as $\beta$-galactosidase ( $\beta$-gal) from a $M y f 5^{\text {nlac } Z}$ allele, is seen in the lips of the dermomoyotome ${ }^{16}$, which also express high levels of Pax3 (arrows in Fig. 1d). In contrast, most $\mathrm{Pax}^{+} \mathrm{Pax}^{+}$cells in the myotome do not co-express Myf5 (about 93\% are Myf5 ${ }^{-}$) (Fig. 1d and Supplementary Fig S1a). This lack of co-expresison is also seen for other markers of cell engagement in the myogenic programme, such as desmin (Supplementary Fig. S1b) or MyoD (Fig. 1f). No coexpression was detected for sarcomeric myosin heavy chain (MyHC) (Fig. 1g), which marks differentiated cells.

The $\mathrm{Pax} 3^{+} \mathrm{Pax} 7^{+}$population shows labelling with a mitotic marker (Fig. 1h), indicating the presence of dividing cells. We examined the proliferation of this population compared to the myogenic cells in the myotome, using co-localization with cyclin A, a marker of S and G2 phases (which represent about $50 \%$ of the cell cycle length). Data presented in Fig. $1 \mathrm{~m}-\mathrm{o}$, bottom panels and quantified in Fig. 1p show that about $96 \%$ of the Pax $3^{+}$cells in the dermomyotome are dividing, as are $81 \%$ of the $\mathrm{Pax} 3^{+} \mathrm{Pax} 7^{+}$progenitors in the myotome. In contrast, less than $20 \%$ of the $\mathrm{MyoD}^{+}$ cells in the myotome are proliferating (Fig. 1o, bottom panel) and only $8 \%$ of the Myf5 $\left(\beta\right.$-gal) ${ }^{+}$cells are proliferating (Fig. 1 , bottom panel), although this lower figure for Myf5 probably reflects $\beta$-gal stability from the $M y f 5^{\text {nLacZ }}$ allele with labelling of some differentiating muscle cells. Of the total number of cyclinA-positive cells in the myotome, $76 \%$ are $\mathrm{Pax}^{+}$(Fig. $1 \mathrm{~m}$, lower panel). We conclude that the $\mathrm{Pax} 3^{+} \mathrm{Pax} 7^{+}$cells constitute the main proliferating population of the myotome. Cells that are not detected as proliferating might reflect heterogeneity in the cell population, or might correspond to cells that are progressing into the myogenic programme, but for which Pax3 expression is still detectable.

Analysis of skeletal muscle masses at later stages shows that the $\mathrm{Pax}^{+} \mathrm{Pax}^{+}$population persists and continues to be distinct from cells that have entered the myogenic programme. MyoD, which marks the myogenic cells, does not co-localize with Pax7, as determined either by staining with an antibody recognizing Pax7 (Fig. 1i, right panel) or by a more sensitive assay using an antibody to $\beta$-gal generated from the $\operatorname{Pax} 7^{\text {LacZ }}$ allele ${ }^{18}$ (Fig. 1j, right panel). Similar results were obtained at all stages examined (E11.5-E17.5; Figs 2, 3, Supplementary Fig. S1 and data not shown). At later stages, $\mathrm{Pax}^{+} \mathrm{Pax}^{+}$cells are also actively dividing (Fig. $1 \mathrm{k}$, right panel). They are also clearly distinct from connective tissue, which is labelled using an antibody against T-cell factor 4 (TCF4) (ref. 19; Fig. 11, right panel).

Having identified a novel $\mathrm{Pax}^{+} \mathrm{Pax}^{+}$population of proliferating cells distinct from the myogenic cells of skeletal muscle, we then investigated whether this population contributes to the growth of 
this tissue. We took advantage of the fact that the products of different reporter genes targeted to the Pax3 and Pax7 $\operatorname{loci}^{18}$ have different stabilities (Fig. $2 \mathrm{~s}$ and Supplementary Fig. S2). GFP, encoded by the reporter sequence that we targeted to Pax3 (F.R and M.B., unpublished data), is more stable than $\beta$-gal generated from the Pax3 $3^{\text {IRESnLacZ/+ }}$ or Pax $7^{\text {LacZ/+ }}$ alleles ${ }^{18,20}$, which has comparable stability to the endogenous proteins (Supplementary Fig. S2). Most $(93 \%)$ of $\beta$-gal ${ }^{+}$cells detected in trunk muscles of Pax $7^{\text {LacZ/+ }}$ mice at E13.5 or E15.5 do not co-express desmin (Fig. 2a-d, j-1), but they do co-localize with the $\mathrm{GFP}^{+}$cells generated from the Pax3 GFP/+ allele (Fig. 2e). However, there are additional $\mathrm{GFP}^{+}$cells that are not $\beta$-gal ${ }^{+}$(Fig. 2e), and all of these co-localize with desmin at E13.5 (Fig. 2f). Similar results were obtained at E15.5, when multinucleated muscle fibres are clearly both GFP- and desmin-positive (Fig. $2 \mathrm{~m}-\mathrm{o}$ ), in contrast to some individual cells labelled only with GFP (arrows in Fig. $2 \mathrm{~m}-\mathrm{o})$. In addition, nearly all $(87 \%)$ of the $\mathrm{Pax}^{+}$cells are dividing, as shown by co-expression of Ki67, which marks cycling cells (Fig. $2 \mathrm{~g}-\mathrm{i}$ ), whereas only $9 \%$ of the $\mathrm{GFP}^{+} / \mathrm{Pax}^{-}$cells co-express Ki67 (data not shown). At this stage, $89 \%$ of cycling cells located within the muscle masses express Pax7, demonstrating that the $\mathrm{Pax}^{+} / \mathrm{Pax} 7^{+}$progenitors constitute the main proliferating cell population (Fig. $2 \mathrm{~g}-\mathrm{i}$ ).
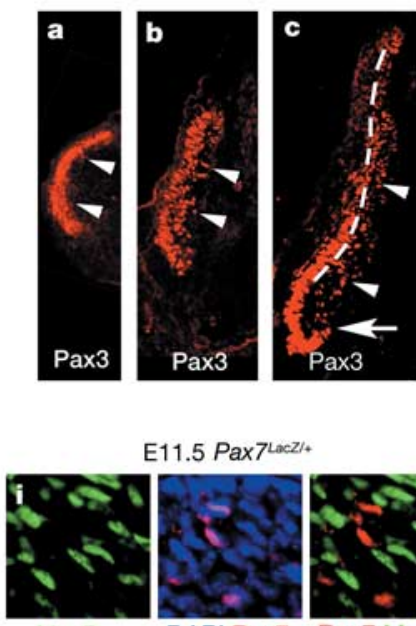

E11.5 Pax7lacz
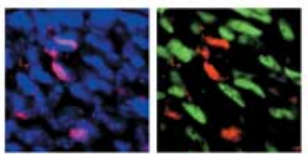

MyoD

DAPI Pax7
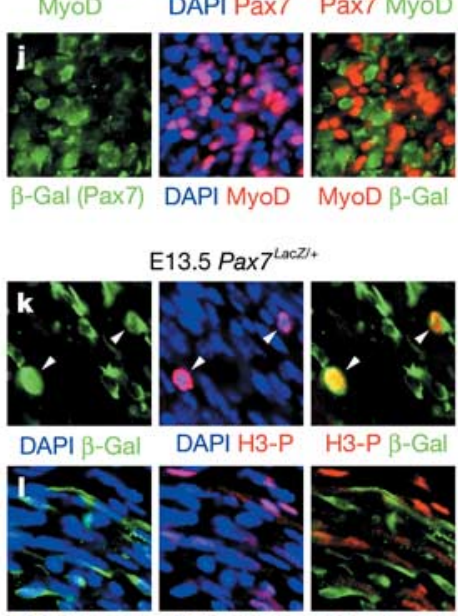

E13.5 Pax $7^{\text {LacZl }}$

DAPI $\beta-G a$

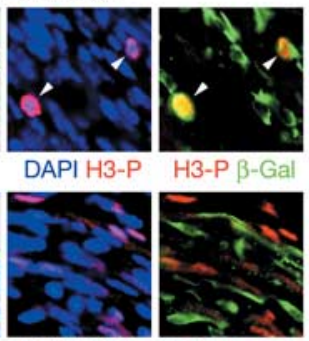

DAPI TCF4 TCF4 B-Ga

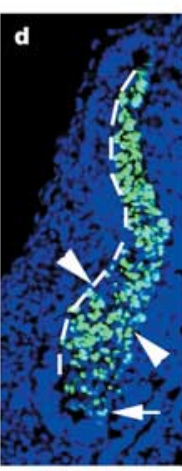

DAPI $\beta-G a l$

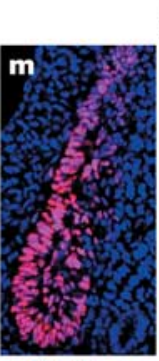

DAPI Pax3

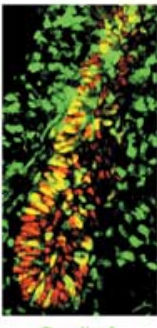

CyclinA

Pax3
E10.75 Myf5

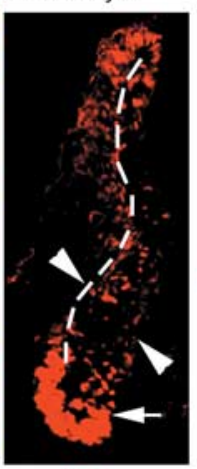

Pax3

E10.5 Myf5

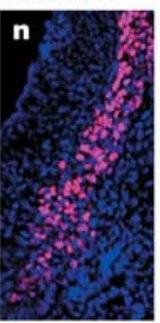

DAPI $\beta$-Gal

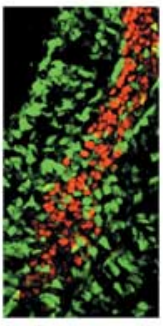

CyclinA B-Gal

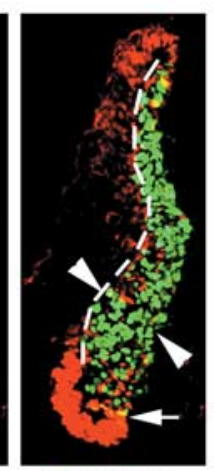

Pax3 $\beta-G a l$

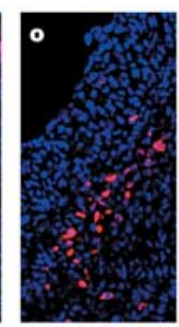

DAPI MyoD

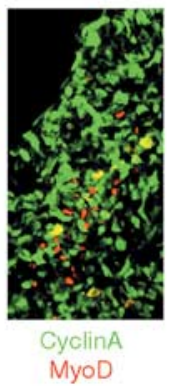

E10.5 Pax3 $3^{\text {(RESnLaCZ/* }}$
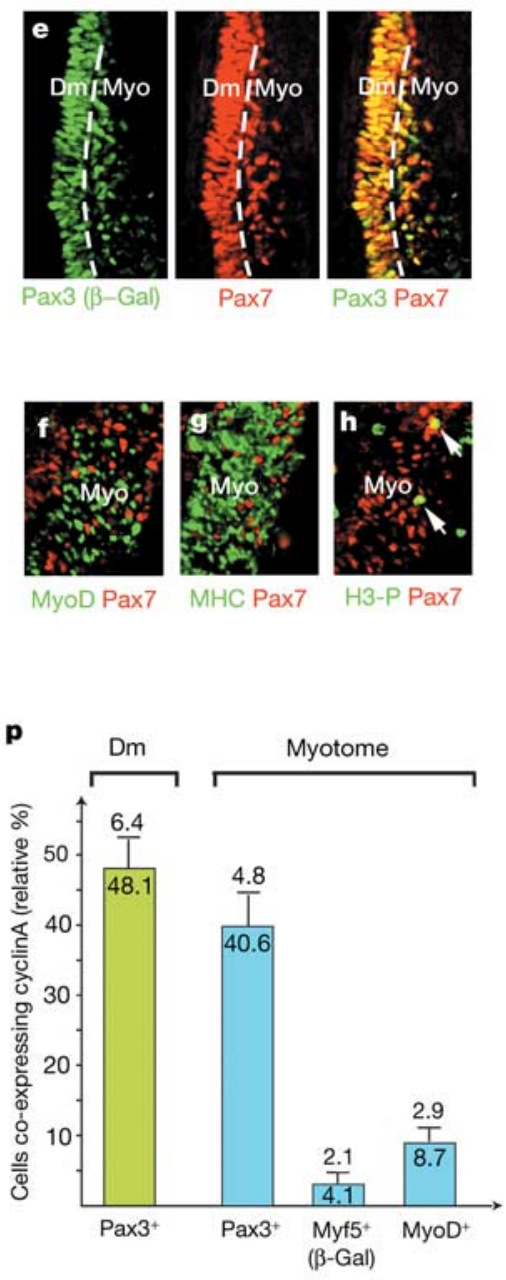

recognizing $\beta$-gal and Pax7, showing co-localization in the myotome. Dm, dermomyotome, Myo, myotome. $\mathbf{f}-\mathbf{h}$, Co-immunohistochemistry on transverse sections of hypaxial thoracic somites from embryos at E10.5, using antibodies recognizing Pax7 and MyoD (f), MyHC (MHC) (g) or phosphorylated histone $\mathrm{H} 3(\mathrm{H} 3-\mathrm{P}, \mathbf{h})$, showing that $\mathrm{Pax}^{+}$cells are dividing. i-I, Co-immunohistochemistry on transverse sections of E11.5 shoulder muscle $(\mathbf{i}, \mathbf{j})$ and hypaxial trunk muscle $(\mathbf{k}, \mathbf{I})$ from $\operatorname{Pax} 7^{\text {LacZ/+ }}$ embryos at E13.5 using antibodies directed against MyoD and Pax7 (i), MyoD and $\beta$-gal (j), H3-P and $\beta$-gal (k), and TCF4 and $\beta$-gal (I), showing that $\mathrm{Pax} 7^{+}$cells are dividing and independent of connective tissue.

$\mathbf{m}-\mathbf{0}$, Co-immunohistochemistry on transverse sections of trunk somites from Myf5 $5^{\text {LLacZ/+ }}$ embryos at E10.5 using antibodies recognizing Pax3 (m), $\beta$-gal (n), MyoD (o) and cyclin A (bottom panels in $\mathbf{m}-\mathbf{0})$. DAPI staining is shown in the top panels of $\mathbf{m}-\mathbf{o}$. The hypaxial region is shown with Pax3-positive cells expressing cyclin A, whereas this is the case for only a few Myf5( $(\beta \text {-gal })^{+}$or MyoD ${ }^{+}$cells. $p$, Quantification of $\geq 6$ sections from at least two different embryos as shown in $\mathbf{m}-\mathbf{0}$. Error bars indicate standard deviation. dermomyotome (on the left) and the myotome.

e, Co-immunohistochemistry on transverse sections of hypaxial thoracic somites from a Pax $3^{I R E S n L a c Z /+}$ embryo at E10.5, using antibodies 
These observations strongly suggest that the dividing $\mathrm{Pax} 3^{+} \mathrm{Pax} 7^{+}$ cells provide a major source of myogenic cells for the formation of skeletal muscle fibres. When the $\mathrm{Pax} 3^{\mathrm{GFP} /+}$ line is crossed with $M y f 5^{\text {nlacZ/+ }}$ mice, all $\beta$-gal ${ }^{+}$cells are also $\mathrm{GFP}^{+}$(Fig. $2 \mathrm{p}-\mathrm{r}$ ). Identical results were obtained with GFP and MyoD (Supplementary Fig. S1g-i and data not shown).
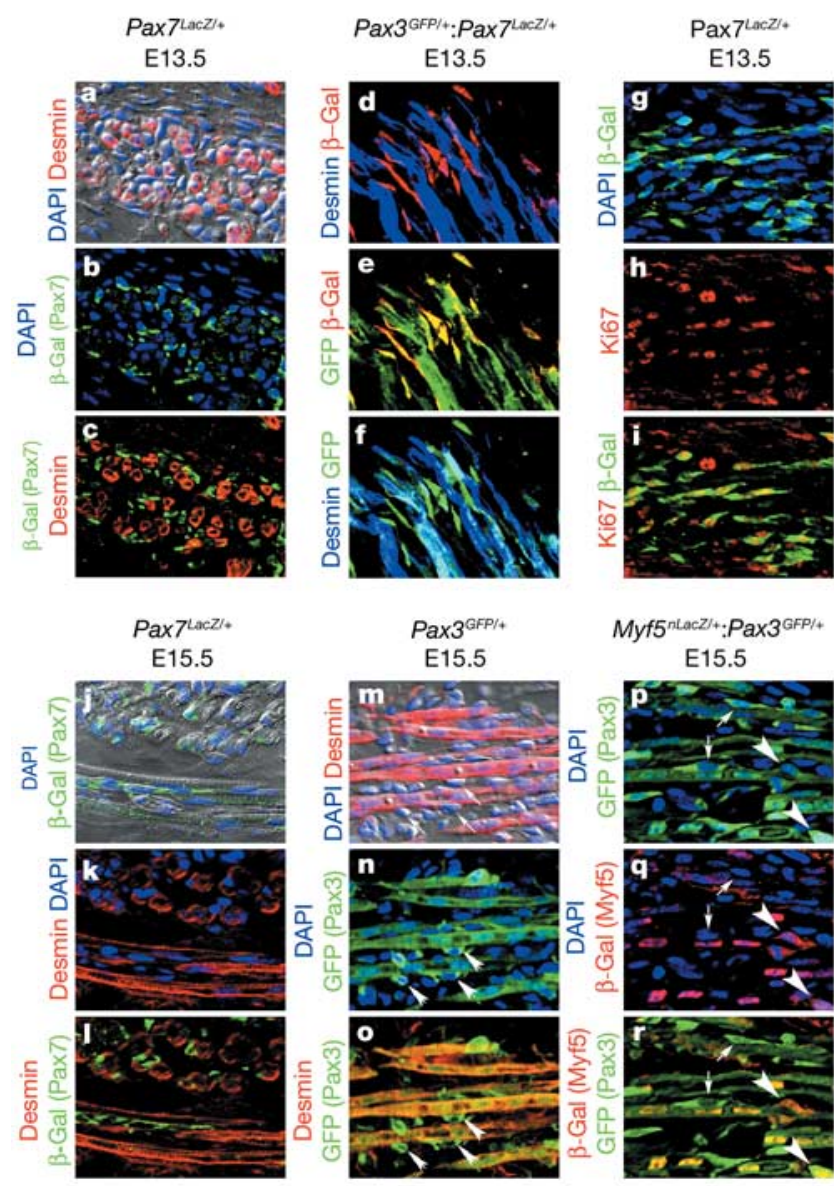
E15.5
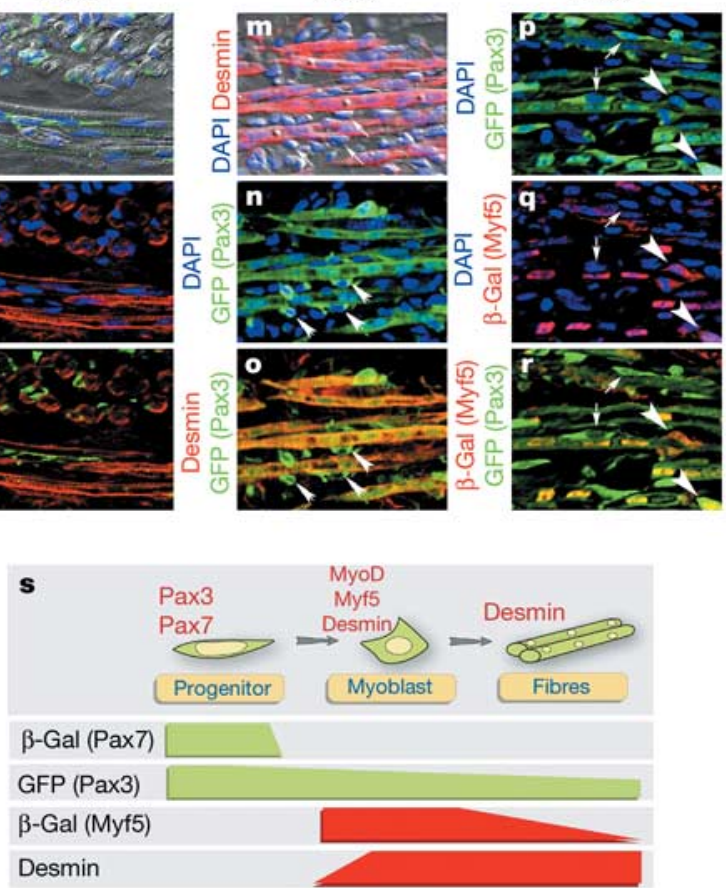

Figure $2 \mid \mathrm{Pax3}^{+} \mathrm{Pax7}^{+}$cells contribute to skeletal muscle. a-i, Coimmunohistochemistry at E13.5 on transverse sections from hypaxial trunk muscle of $\mathrm{Pax}^{\mathrm{LacZ} /+}(\mathbf{a}-\mathbf{c}, \mathbf{g}-\mathbf{i})$ or $\mathrm{Pax}^{\mathrm{GFP} /+}: \mathrm{Pax}^{\mathrm{LacZ} /+}$ (d-f) embryos, using antibodies directed against desmin $(\mathbf{a}, \mathbf{c}, \mathbf{d}, \mathbf{f}), \beta-\operatorname{gal}(\mathbf{b}-\mathbf{e}, \mathbf{g}, \mathbf{i})$, or Ki67 $(h, i)$. Phase-contrast image shown in $a$, GFP fluorescence in $\mathbf{e}, \mathbf{f}$ and DAPI staining in a, b, g. j-r, Co-immunohistochemistry at E15.5 on transverse sections from hypaxial trunk muscle of $\operatorname{Pax}^{\mathrm{LacZ} /+}(\mathbf{j}-\mathbf{I}), \operatorname{Pax}^{\mathrm{GFP} /+}(\mathbf{m}-\mathbf{0})$ or $M y f 5^{\text {nLacZ/+ }}: P a x 3^{G F P /+}$ (p-r) embryos, using antibodies directed against $\operatorname{desmin}(\mathbf{k}-\mathbf{m}, \mathbf{0}), \beta-\operatorname{gal}(\mathbf{j}, \mathbf{l}, \mathbf{q}, \mathbf{r})$ or GFP $(\mathbf{n}-\mathbf{p}, \mathbf{r})$. Phase-contrast images are shown in $\mathbf{j}, \mathbf{m}$, and DAPI staining is shown in $\mathbf{j}, \mathbf{k}, \mathbf{m}, \mathbf{n}, \mathbf{p}, \mathbf{q} . \mathrm{GFP}^{+}$desmin cells and $\mathrm{GFP}^{+} \beta$-gal ${ }^{-}$cells are indicated by white arrows in $\mathbf{m}-\mathbf{r}$. $\mathrm{GFP}^{+} \beta-$ $\mathrm{gal}^{+}$myogenic cells are shown with arrowheads in p-r. s, Schematic showing the endogenous expression of Pax 3 and Pax7 in resident muscle progenitor cells, the expression of Myf5 and MyoD in muscle myoblasts, and desmin in myoblasts and muscle fibres. This expression is compared with the relative expression of the LacZ, GFP and nLacZ reporter proteins generated from, $\operatorname{Pax} 7^{\mathrm{LacZ}}, \operatorname{Pax}^{\mathrm{GFP}}$ and $M y f 5^{\text {nLacZ }}$ alleles, respectively.
We then investigated whether our findings on trunk muscles could be generalized to the limb, where the myogenic cells are derived from a progenitor cell population that migrates from the somites ${ }^{14,15}$. These cells express Pax3 but not Pax7, which is upregulated at E11 in the mouse embryo9. At E13.5, we found that cells expressing $\operatorname{Pax} 7^{\mathrm{LacZ} /+}$ are distinct from the desmin-positive muscle cells of the limb (Supplementary Fig. S1c-f). Analysis of $\mathrm{Pax} 3^{\mathrm{GFP} /+}: \mathrm{Pax} 7^{\mathrm{LacZ} /+}$ embryos at this stage also showed that all the $\mathrm{Pax} 7^{+}$cells express GFP (Supplementary Fig. S1d-f) and that all the $\mathrm{MyoD}^{+}$myogenic cells, which do not express Pax7, are marked by GFP (Supplementary Fig. S1g-1). We conclude that the $\operatorname{Pax} 3^{+} \operatorname{Pax} 7^{+}$cells constitute a novel compartment of resident muscle progenitor cells that contribute to muscle growth during development both in the limbs and trunk.

By E15.5, cells that are $\mathrm{Pax}^{+}{ }^{+}$but Myf5 $(\beta-\text { gal })^{-}$are located along, and in close contact with, the muscle fibres (Fig. 2p-r). Between E16.5 and E18.5 a basal lamina, marked by laminin expression, forms around the muscle fibres, including the associated $\mathrm{Pax} 3^{+} \mathrm{Pax} 7^{+}$cells (Fig. 3a-o and Supplementary Fig. S1m-o). This location, under the basal lamina and in close proximity to the muscle fibre, is characteristic of satellite cells, which are the progenitor cells of postnatal skeletal muscle ${ }^{21}$ and have been shown to originate from the somite in the chick embryo ${ }^{22}$. In the mouse, these cells express Pax7 (ref. 10), and in a subset of skeletal muscles also express Pax3 (F.R. and M.B., unpublished data). We found that $P a \times 3^{G F P /+}$ cells become embedded under the basal lamina by E18.5 (Fig. 3m-O and Supplementary Fig. S1m-o) and are still detectable during postnatal growth (Fig. 3p-r). We suggest that the resident muscle progenitor cells present in embryonic and fetal muscle later constitute the satellite cell

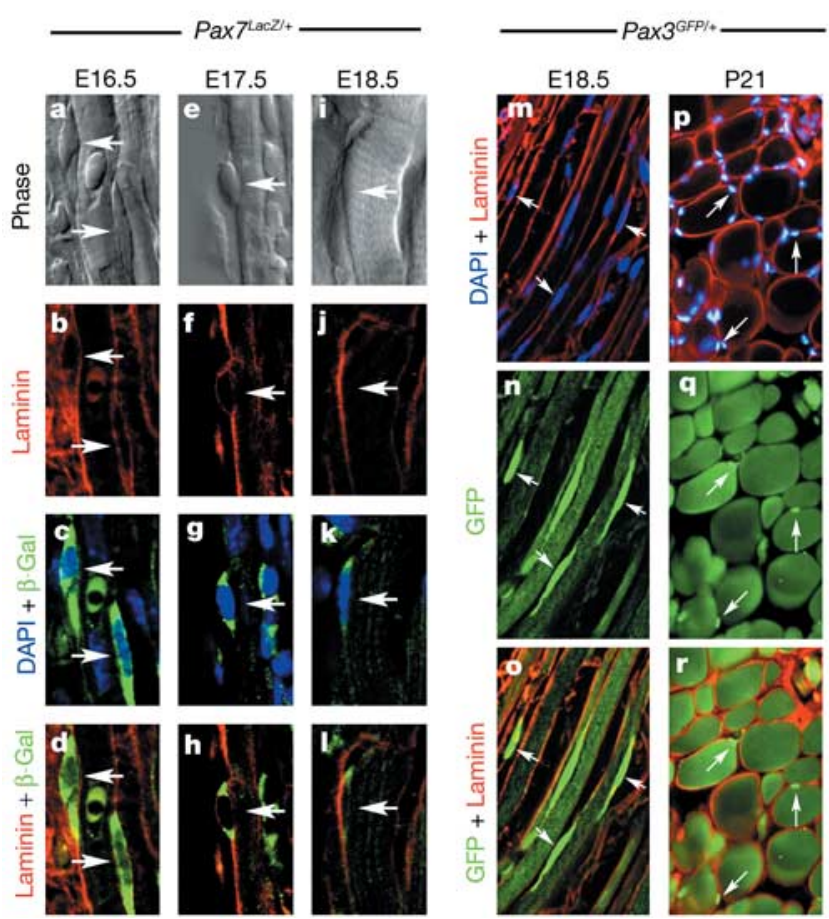

Figure 3 | $\mathrm{Pax}^{+} \mathrm{Pax}^{+}$progenitors adopt a satellite cell position from late fetal stages. a-I, Co-immunohistochemistry on hypaxial trunk muscle from $\operatorname{Pax} 7^{\mathrm{LacZ} /+}$ fetuses at E16.5 (a-d), E17.5 (e-h) and E18.5 (i-l), using DAPI staining $(\mathbf{c}, \mathbf{g}, \mathbf{k})$ and antibodies directed against laminin $(\mathbf{b}, \mathbf{d}, \mathbf{f}, \mathbf{h}, \mathbf{j}, \mathbf{I})$ and $\beta$-gal $(\mathbf{c}, \mathbf{d}, \mathbf{g}, \mathbf{h}, \mathbf{k}, \mathbf{I})$. Phase-contrast images shown in $\mathbf{a}, \mathbf{e}, \mathbf{i} . \beta$-gal ${ }^{+}$cells become embedded in the basal lamina and adopt satellite cell positions (indicated with white arrows). $\mathbf{m}-\mathbf{r}, \mathbf{C o}$-immunohistochemistry on hypaxial trunk muscle from $\mathrm{Pax} 3{ }^{\mathrm{GFP} /+}$ embryos at E18.5 (m-o) or three-week-old (P21) mice (p-r) using DAPI staining ( $\mathbf{m}, \mathbf{p})$ and antibodies directed against laminin $(\mathbf{m}, \mathbf{o}, \mathbf{p}, \mathbf{r})$ and $\operatorname{GFP}(\mathbf{n}, \mathbf{0}, \mathbf{q}, \mathbf{r})$. White arrows indicate GFP-positive cells located in a satellite cell position. 
population responsible for postnatal muscle growth and regeneration.

As previously reported, $\operatorname{Pax} 7$ mutants show no overt muscle defect during development ${ }^{9,18}$. In contrast, in the trunk, Pax3 mutant embryos display somite truncations ${ }^{20}$ with loss of the hypaxial dermomyotome (Fig. 4b,e), resulting in the reduction and disorganization of hypaxial trunk musculature ${ }^{3}$ (Fig. 4h, arrowhead). The somites of Pax3/Pax7 double mutants are similar to those of Pax3 mutants until E10.5 (Fig. 4b-c), with initial formation of skeletal muscle in the myotome (Suplementary Fig. S3a, b) under the control of the myogenic regulatory factors Myf5 (ref. 6) and/or Mrf4 (ref. 7).
However, as development proceeds, somites become more severely affected and loss of $\mathrm{Pax}^{+} \mathrm{Pax}^{+}$cells is observed (Fig. 4f). Subsequently, most skeletal muscles of the trunk, such as those of the overlying body wall (Fig. 4i), are severely compromised. By E13.5, only a few muscle fibres are detectable (Fig. 41), and at E11.5 there is already a marked deficit of differentiated muscle cells (Fig. 4o). Pax3 (and Pax7 when substituted for Pax3, ref. 9) assures the survival of early myogenic progenitor cells in the hypaxial dermomyotome ${ }^{4}$. By E11.5, no further apoptosis is observed in the Pax3 mutant, whereas in the Pax3/Pax7 double mutant cell death still occurs (lower panels, Fig. $4 \mathrm{~m}-\mathrm{o}$ ).
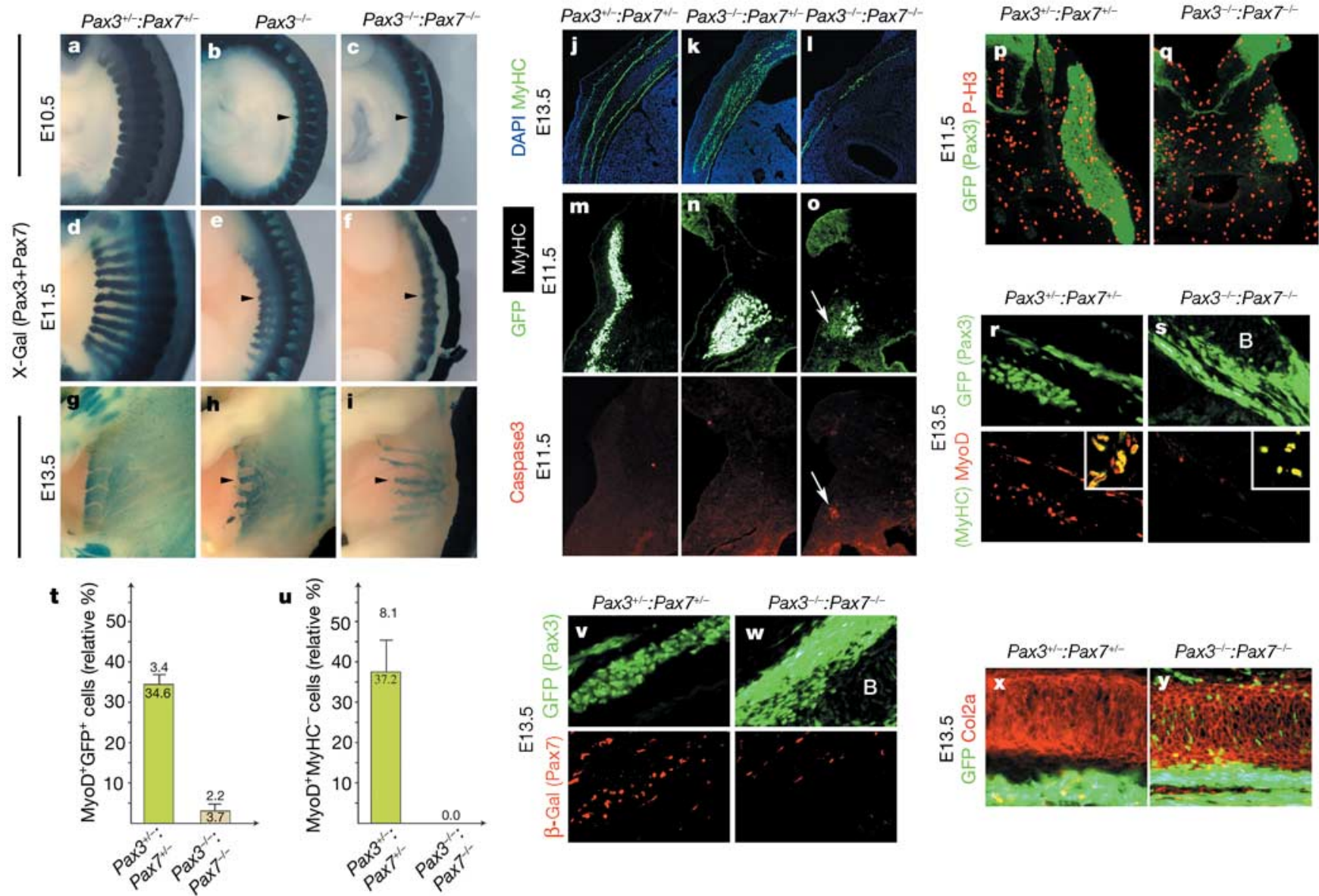

Figure $4 \mid$ Major myogenic defects in Pax3/Pax7 double mutant embryos. $\mathbf{a}-\mathbf{i}, \mathrm{X}$-gal staining of thoracic somites at E10.5 (a-c) and E11.5 (d-f) and of thoracic muscles at E13.5 (g-i) of $\mathrm{Pax}^{\text {nLacZ/+ }}: \mathrm{Pax}^{\mathrm{LacZ} /+}\left(\mathrm{Pax3}^{+/-}: \mathrm{Pax}^{+/-}\right.$, a, d, g), Pax3 ${ }^{\text {nLacZ/nLacZ }}\left(\mathrm{Pax3}^{-/-}, \mathbf{b}, \mathbf{e}, \mathbf{h}\right)$ or Pax3 ${ }^{\text {nLacZ/nLacZ }}: \mathrm{Pax}^{\mathrm{LacZ} / \mathrm{LacZ}}$ $\left(\operatorname{Pax}^{-/-}: \operatorname{Pax}^{-1-}, \mathbf{c}, \mathbf{f}, \mathbf{i}\right)$ embryos. Arrowheads indicate somite and trunk muscle defects. j-I, Immunohistochemistry on transverse sections of body wall muscle of $\mathrm{Pax}^{\mathrm{GFP} /+}: \mathrm{Pax}^{\mathrm{LacZ} /+}\left(\mathrm{Pax}^{+/-}: \mathrm{Pax}^{+/-}, \mathbf{j}\right)$,

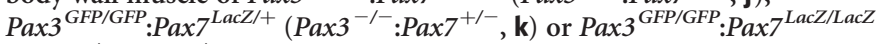
$\left(\operatorname{Pax3}^{-/-}: P a x 7^{-/-}, \mathrm{I}\right)$ embryos at E13.5, using DAPI staining and an antibody against MyHC. Loss of skeletal muscle is seen in the double mutant. $\mathbf{m}-\mathbf{0}$, Co-immunohistochemistry on transverse sections of thoracic somites of E11.5 embryos as in $\mathbf{j}-\mathbf{l}$, using antibodies recognizing MyHC (top panels) and the activated form of caspase 3, which labels apoptotic cells (bottom panels). Endogenous GFP fluorescence is detectable above background and co-localizes with active caspase- 3 (arrow in $\mathbf{0}$ ), indicating that, in contrast to the Pax3 mutant embryos, apoptosis is maintained in the Pax3/Pax7 double mutants at E11.5. p-y, Co-immunohistochemistry ( $\mathbf{p}-\mathbf{s}, \mathbf{v}-\mathbf{y})$ and histograms (t, u) using $\operatorname{Pax}^{\mathrm{GFP} /+}: \mathrm{Pax}^{\mathrm{LacZ} /+}\left(\mathrm{Pax}^{+/-}: \mathrm{Pax}^{+/-}\right)$or Pax $3^{\text {GFP/GFP }}:$ Pax $7^{\text {LacZ/LacZ }}\left(\right.$ Pax $^{-I^{-1}}:$ Pax $\left.7^{-/-}\right)$embryos. p, q, Transverse sections of thoracic somites from E11.5 embryos using antibodies recognizing GFP and phosphorylated histone $\mathrm{H} 3(\mathrm{P}-\mathrm{H} 3)$, which labels mitotic cells. No proliferation defects are observed in the double mutant embryos. r, s, Transverse sections of embryos at E13.5 using antibodies recognizing GFP (top panels), MyoD (bottom panels) and MyHC (insets in bottom panels). Insets show the co-localization (in yellow) of MyoD and MyHC in the control and Pax3/Pax7 double mutants. There are no undifferentiated $\mathrm{MyoD}^{+} / \mathrm{MyHC}^{-}$cells in the double mutants.

$\mathbf{t}$, Quantification of the number of $\mathrm{GFP}^{+}$cells co-expressing MyoD in embryos shown in $\mathbf{r}, \mathbf{s}$ ( $\geq 6$ sections from 2 independent embryos in each case). $\mathbf{u}$, Quantification of the number of $\mathrm{MyoD}^{+}$cells co-expressing MyHC. In contrast to the control embryos, in which $37 \%$ of the MyoD + cells are not terminally differentiated, all the $\mathrm{MyoD}^{+}$cells co-express the differentiation marker $\mathrm{MyHC}$ in the double mutant embryos,

demonstrating that at this stage no $\mathrm{MyoD}^{+}$myogenic cells are contributing to muscle growth. Standard deviations are indicated on the histograms. $\mathbf{v}, \mathbf{w}$, Transverse sections of E13.5 embryos at the level of the rib, which is normally adjacent to intercostal muscle, using antibodies recognizing GFP (top panels) and $\beta$-gal (bottom panels), showing that only cells marked with the stable GFP reporter are still present. In $\mathbf{w}$ (top panel), some $\mathrm{GFP}^{+}$cells localize in the bone (B) of double mutant embryos. $\mathbf{x}, \mathbf{y}$, Transverse sections in E13.5 embryos at the level of the ribs, normally in proximity to hypaxial muscles, using antibodies recognizing GFP and collagen $2 a$ (Col2a) which marks the condensing cartilage of the ribs. In the double mutant, $\mathrm{GFP}^{+}$cells are now located within and in the immediate vicinity of the rib. 
Cell proliferation, another factor that may affect the capacity of $\mathrm{Pax} 3^{+} \mathrm{Pax} 7^{+}$progenitor cells to contribute to muscle growth, does not appear to be affected in the $\mathrm{GFP}^{+}$population in Pax3 ${ }^{\text {GFP/GFP }}$ : Pax7 ${ }^{\text {LacZ/LacZ }}$ mutant embryos (Fig. 4p, q). Notably, GFP-positive cells are still present at E13.5, when there is a marked deficit in skeletal muscle. They are mainly MyoD ${ }^{-}$(Fig. 4r, s, lower panels), and the remaining $\mathrm{MyoD}^{+}$cells $(3.7 \%$ of GFP-expressing cells, compared with $34.6 \%$ in the presence of Pax3 and/or Pax7, Fig. 4t) are all coexpressing terminal differentiation markers (Fig. 4r, s, lower panels, $\mathrm{u}$ ). They probably correspond to differentiated cells dating from the first phase of embryonic myogenesis, when the myotome forms in the absence of Pax3 and Pax7 (Supplementary Fig. S3). This indicates that in the absence of both Pax proteins, myogenic progenitor cells at later embryonic and fetal stages are not specified as skeletal muscle. Instead, they downregulate transcription of the Pax genes, as shown in Fig. $4 \mathrm{v}, \mathrm{w}$, lower panels, where $\beta$-gal from the Pax $7^{\text {LacZ }}$ allele is no longer detectable (3.2\% versus $37.7 \%$ ) in cells in which the more stable GFP reporter produced from the Pax3 ${ }^{G F P}$ allele (Fig. 4s, Fig. 2s and Supplementary Fig. S2) is still present. Identical results to those shown for $\operatorname{Pax} 7^{\text {LacZ }}$ were obtained with a Pax3 ${ }^{\text {IRESnLacZ }}$ allele (data not shown). The GFP-positive mutant cells probably assume non-myogenic fates, as shown by their presence in bones, where they are associated with the expression of markers such as collagen $2 \mathrm{a}(\mathrm{Col} 2 \mathrm{a}$, Fig. 4y), which is characteristic of cartilage cells.

Our results show that after the initial formation of the myotome, which has been a focus in the study of myogenic regulation ${ }^{2,16}$, subsequent embryonic myogenesis depends on the expression of Pax3 and Pax7, making these factors key upstream regulators of the myogenic process. In the absence of both Pax proteins, resident muscle progenitor cells do not enter the myogenic programme. Double mutants die at mid-gestation, but given the persistence of this cell population and its demonstrated contribution to fetal muscles, we conclude that the skeletal musculature of the fetus also depends on Pax3 and Pax7. The apparent acquisition of satellite cell properties by the $\mathrm{Pax} 3^{+} \mathrm{Pax} 7^{+}$cells in late fetal muscle suggests that the progenitor cells of postnatal and adult muscle also derive from this population. These cells are compromised in the Pax7 mutant ${ }^{10}$, but some satellite cells are still detectable, suggesting that they are specified correctly ${ }^{11}$; furthermore, there is no deficit in satellite cells immediately postnatally (F.R., D. Montarras and M.B., unpublished data). This is consistent with a requirement for either Pax3 or Pax7 to generate the cell pool of muscle progenitors from which satellite cells derive. Complementary observations on the origin of the $\mathrm{Pax} 3^{+} \mathrm{Pax} 7^{+}$population from the dermomyotome of the chick embryo using long-term lineage tracing ${ }^{23}$ suggest that the progenitor cells of fetal and postnatal muscle derive from the paraxial mesoderm of the embryonic somite.

The resident muscle progenitor cells that we have identified constitute the principal proliferative cell population of developing skeletal muscle. It is important to determine whether these cells selfrenew as a true stem cell population (see Figs $1 \mathrm{~m}-\mathrm{p}$ and $2 \mathrm{~g}-\mathrm{i}$ ). Pax3 and Pax7 have an important role in conferring myogenic potential on these progenitor cells, thus assuring the major phases of skeletal muscle formation as the organism develops. Such cells represent a potentially exploitable resource in the context of cell therapy for muscle diseases.

\section{METHODS}

Mice. Generation and genotyping of the Pax $3^{\text {nLacZ/+ }}, \operatorname{Pax}^{\text {IRESnLacZ/+ }}$ and $\operatorname{Pax}^{\text {LacZ/+ }}$ alleles have been previously described ${ }^{9,18,20}$. The Pax3 ${ }^{\text {GFP/+ }}$ allele will be described elsewere in detail. Briefly, enhanced (E)GFP replaces the Pax3 coding sequence of exon 1, as previously reported for DsRed in the Pax $3^{\text {DsRed/ }+}$ allele?.

$\mathrm{X}$-Gal staining, histology, immunohistochemistry and in situ hybridization. $\mathrm{X}$-Gal staining, histology, immunohistochemistry and whole-mount in situ hybridization were performed as previously reported ${ }^{9}$. Antibodies used were as follows: MyoD, either a rabbit polyclonal (Santa Cruz; 1:200 dilution) or a mouse monoclonal antibody (clone 5.8A, DAKO; 1:200); desmin, mouse monoclonal antibody (clone D33, DAKO; 1:200); laminin, either a mouse monoclonal (clone 4C7, DAKO; 1:100) or a rabbit polyclonal antibody (Sigma; 1:200); Pax7, mouse monoclonal antibody (Developmental Studies Hybridoma Bank; 1:100); Pax3, mouse monoclonal antibody (provided by M. Bronner-Fraser; 1:100); $\beta$-gal, either a rabbit polyconal (provided by J.-F. Nicolas; $1: 500$ ) or a mouse monoclonal antibody (clone Gal13, SIGMA; 1:100); phospho-histone H3, mouse monoclonal antibody (Cell Signalling; 1:200); TCF4, chicken polyclonal antibody (provided by G.R. Dressler; 1:200); MyHC, rabbit polyclonal antibody (provided by G. Cossu; 1:250); GFP, mouse monoclonal antibody (Biovalley; 1:1,000); Col2a, mouse monoclonal antibody (abcam; 1:100); Ki67, rabbit polyclonal antibody (Pharmingen; 1:200); cyclin A, rabbit polyclonal antibody (provided by A. Fernandez; 1:200).

Secondary antibodies were coupled to a fluorochrome, Alexa 350, 488, 546, 594 or 647 (Molecular Probes), used at 1:250 (Alexa 350 and 488) or 1:1,500 (Alexa 546, 594 or 647) dilutions. Images are obtained with Apotome Zeiss and Axiovision software. This system provides an optical section view reconstructed from fluorescent samples, using a series of 'grid projection' (or 'structured illumination') acquisitions. Figures were assembled using the Photoshop CS application (Adobe) and a PowerMacG4. Percentage figures given in the text on antibody labelling were based on the analysis of $\geq 6$ sections from at least two embryos.

\section{Received 31 January; accepted 6 April 2005.}

\section{Published online 20 April 2005.}

1. Cossu, G. in Advances in Developmental Biology and Biochemistry (ed. Wassarman, P. M.) 127-142 (Elsevier, San Diego, 2001).

2. Pownall, M. E., Gustafsson, M. K. \& Emerson, C. P. Jr Myogenic regulatory factors and the specification of muscle progenitors in vertebrate embryos. Annu. Rev. Cell Dev. Biol. 18, 747-783 (2002)

3. Tremblay, P. et al. A crucial role for Pax3 in the development of the hypaxial musculature and the long-range migration of muscle precursors. Dev. Biol. 203, 49-61 (1998)

4. Borycki, A. G., Li, J., Jin, F., Emerson, C. P. \& Epstein, J. A. Pax3 functions in cell survival and in pax7 regulation. Development 126, 1665-1674 (1999).

5. Buckingham, M. et al. The formation of skeletal muscle: from somite to limb. J. Anat. 202, 59-68 (2003).

6. Tajbakhsh, S., Rocancourt, D., Cossu, G. \& Buckingham, M. Redefining the genetic hierarchies controlling skeletal myogenesis: Pax-3 and Myf-5 act upstream of MyoD. Cell 89, 127-138 (1997).

7. Kassar-Duchossoy, L. et al. Mrf4 determines skeletal muscle identity in Myf5:Myod double-mutant mice. Nature 431, 466-471 (2004).

8. Rudnicki, M. A. et al. MyoD or Myf-5 is required for the formation of skeletal muscle. Cell 75, 1351-1359 (1993).

9. Relaix, F., Rocancourt, D., Mansouri, A. \& Buckingham, M. Divergent functions of murine Pax3 and Pax7 in limb muscle development. Genes Dev. 18, 1088-1105 (2004)

10. Seale, P. et al. Pax7 is required for the specification of myogenic satellite cells. Cell 102, 777-786 (2000)

11. Oustanina, S., Hause, G. \& Braun, T. Pax7 directs postnatal renewal and propagation of myogenic satellite cells but not their specification. EMBO J. 23, 3430-3439 (2004)

12. Schubert, F. R. et al. Early mesodermal phenotypes in splotch suggest a role for Pax3 in the formation of epithelial somites. Dev. Dyn. 222, 506-521 (2001)

13. Williams, B. A. \& Ordahl, C. P. Pax-3 expression in segmental mesoderm marks early stages in myogenic cell specification. Development 120, 785-796 (1994).

14. Bober, E., Franz, T., Arnold, H. H., Gruss, P. \& Tremblay, P. Pax-3 is required for the development of limb muscles: a possible role for the migration of dermomyotomal muscle progenitor cells. Development 120, 603-612 (1994).

15. Goulding, M., Lumsden, A. \& Paquette, A. J. Regulation of Pax-3 expression in the dermomyotome and its role in muscle development. Development 120, 957-971 (1994).

16. Tajbakhsh, S. \& Buckingham, M. The birth of muscle progenitor cells in the mouse: spatiotemporal considerations. Curr. Top. Dev. Biol. 48, 225-268 (2000)

17. Jostes, B., Walther, C. \& Gruss, P. The murine paired box gene, Pax7, is expressed specifically during the development of the nervous and muscular system. Mech. Dev. 33, 27-37 (1990).

18. Mansouri, A., Stoykova, A., Torres, M. \& Gruss, P. Dysgenesis of cephalic neural crest derivatives in $\mathrm{Pax}^{-/-}$mutant mice. Development 122, 831-838 (1996).

19. Kardon, G., Harfe, B. D. \& Tabin, C. J. A Tcf4-positive mesodermal population provides a prepattern for vertebrate limb muscle patterning. Dev. Cell 5, 937-944 (2003)

20. Relaix, F. et al. The transcriptional activator PAX3-FKHR rescues the defects of Pax3 mutant mice but induces a myogenic gain-of-function phenotype with ligand-independent activation of Met signaling in vivo. Genes Dev. 17, 2950-2965 (2003) 
21. Mauro, A. Satellite cell of skeletal muscle fibers. J. Biophys. Biochem. Cytol. 9, 493-495 (1961)

22. Armand, O., Boutineau, A. M., Mauger, A., Pautou, M. P. \& Kieny, M. Origin of satellite cells in avian skeletal muscles. Arch. Anat. Microsc. Morphol. Exp. 72, 163-181 (1983).

23. Gros, J., Manceau, M., Thomé, V. \& Marcelle, C. A common somitic origin for embryonic muscle progenitors and satellite cells. Nature advance online publication, 20 April 2005 (doi:10.1038/nature03572).

24. Tajbakhsh, S., Rocancourt, D. \& Buckingham, M. Muscle progenitor cells failing to respond to positional cues adopt non-myogenic fates in myf-5 null mice. Nature 384, 266-270 (1996).

25. Ben-Yair, R. \& Kalcheim, C. Lineage analysis of the avian dermomyotome sheet reveals the existence of single cells with both dermal and muscle progenitor fates. Development 132, 689-701 (2005).
Supplementary Information is linked to the online version of the paper at www.nature.com/nature.

Acknowledgements We thank B. Williamson for critical reading of the manuscript and C. Bodin for histology work. This work was supported by the Pasteur Institute and the CNRS, with additional grants from the A.F.M., the 'Cellules Souches' Grand Programme Horizontal of the Pasteur Institute, the Cells into Organs Network of Excellence and the EuroStemCell Integrated Project of the EU Sixth Framework Programme.

Author Information Reprints and permissions information is available at npg.nature.com/reprintsandpermissions. The authors declare no competing financial interests. Correspondence and requests for materials should be addressed to F.R (frelaix@pasteur.fr) or M.B. (margab@pasteur.fr). 